\title{
Halo Vest Treatment of Upper Cervical Vertebral Fracture
}

\author{
Serhat Yıldızhan (D), Mehmet Gazi Boyacı (D) \\ Department of Neurosurgery, Afyonkarahisar Health Sciences University School of Medicine, Afyonkarahisar, Turkey
}

Cite this article as: Yıldızhan S, Boyacı MG. Halo Vest Treatment of Upper Cervical Vertebral Fracture. JAREM 2019; 9(Supplement 1): S10-4.

\begin{abstract}
Objective: Spinal trauma and cervical fractures are one of the most common causes of mortality and morbidity in the elderly. Surgical interventions can result in high rates of complications due to age of the patients and additional diseases. In our study, we investigated the long-term follow-up results in patients who applied the HALO Vest following the upper cervical C1 and C2 vertebral fractures.

Methods: A total of 30 patients ( 20 male, 10 female), who were applied the HALO Vest in our clinic due to fractures of the cervical C1 and C2 vertebrae after any trauma between 2013 and 2017, were studied. Patients who developed infection, congenital anomaly, or post-malignancy fracture were not included in the study. Patients were followed up by computed tomography and flexion-extension radiographies. The HALO Vest of fusion patients was removed.

Results: There were 2 isolated C1 fractures, 6 C1+C2 odontoid Type 2 fractures, 16 isolated odontoid fractures, 2 C2 massa lateralis fractures, and 4 Hangman fractures in a total of 30 patients with the HALO Vest device. Patients were followed for 15 weeks on average (10-22 weeks) with the HALO Vest immobilization device. As a result, a full fusion in 22 patients and partial fusion in 8 remaining patients due to different reasons were found. The HALO Vest patients were followed up using the Philadelphia cervical collar. Infection occurred in 5 patients. Nail positions were changed in 1 patient.

Conclusion: The application of the HALO Vest device in selected patients with the upper cervical vertebra fractures is a very reliable and effective treatment method for various difficulties encountered by the patient.
\end{abstract}

Keywords: Trauma, upper cervical fractures, HALO vest immobilization, fusion

\section{INTRODUCTION}

Today, one of the most common causes of mortality and morbidity is spinal trauma and cervical fractures, occurring accordingly. Cervical fractures account for $>60 \%$ of spinal traumas (1). Approximately $2 \%-15 \%$ of acute cervical fractures are seen at the C1 level, and $17 \%-25 \%$ are seen at the C2 level (2). C1-C2 combined fractures constitute $3 \%$ of all cervical fractures (3). In 1933, Crutchfield started the modern treatment in this area, using a skeletal traction device for spinal trauma (1). Many treatments have been proposed for the treatment of cervical fractures since then, but there is still no consensus. Conservative treatment immobilization methods applied today include rigid cervical orthosis, cervicothoracic orthosis (Minerva), and HALO Vest. Among these methods, HALO Vest, which is the most commonly used method, was first used by Perry and Nickel in 1959 (4). The reasons for using the HALO Vest device more and more widely are that it provides a more rigid immobilization balance, is easy to apply, reduces the patient's dependence on the bed and the length of stay in the hospital, and enables to provide the desired longitudinal position.
Atlas (C1) fractures are divided into four groups. These are fracture of the posterior arch of $\mathrm{C} 1$, fracture of the massa lateralis of $\mathrm{C} 1$, transverse fracture of the anterior arch of $\mathrm{C} 1$, and horizontal fracture of the anterior arch of $\mathrm{C} 1$. While external immobilization is sufficient for isolated C1 fractures, C1-C2 fusion is needed in cases where the massa lateralis is displaced $>7 \mathrm{~mm}$ on AP radiography.

Today, Anderson D'Alonzo is the most widely used method in cervical odontoid fracture classification. Accordingly, odontoid fractures are divided into three groups as follows:

Type 1: Oblique avulsion fractures occurring at the dens above the top of the transverse ligament. They are rare and usually stable fractures.

Type 2: Fractures occurring on the base of the odontoid protrusion. They are the most common type of fracture. They are mostly unstable fractures.

Type 3: It is the progression of the fracture line from the odontoid base to the axle body. Some type 3 fractures may have frag- 
ments extending from the base of the dens to the base with fractures; such fractures are considered as type 2A fractures. Typical type 3 fractures can be treated with orthoses. If the fracture line has affected the axis upper joint surface, they are defined as type 3 fractures.

\section{METHODS}

A total of 30 patients who were followed up for upper cervical fracture in our clinic between January 1, 2013 and December 31, 2017 and who had a HALO Vest immobilization device were included in the present study. The study was approved by the Afyon Kocatepe University Clinical Research Ethics Committee (decision dated 02/03/2017 and no. 2017/2-40). Verbal consent was obtained from the patients. The selection criteria for the development of cervical fracture were determined as traffic accident or fall. Patients with upper cervical vertebra fractures following malignancies, congenital anomalies, or infections were excluded from the study. All patients underwent direct radiography, computed tomography, and magnetic resonance imaging after application. The patients were checked with scopy under operating room conditions, and the HALO Vest device was duly installed. The patients were followed up on an average of 15 (10-22) weeks with the HALO Vest device. During the follow-up, the patients were evaluated clinically and radiologically at $1,4,6,8,10$, and 12 weeks. During the follow-up period, in patients who developed fusion from 10 weeks, the device was removed and followed by a Philadelphia cervical collar for another 4 weeks. The neck collars of the patients who were found to have fusion during follow-up with a Philadelphia collar were removed. The fusion was established by the complaints of the patients and the presence of sensitivity in the cervical region in the clinical evaluation and trabeculation along the fracture line and radiological follow-up of the fracture line in the radiological evaluation.

\section{Statistical Analysis}

Data were analyzed using Statistical Package for Social Sciences, version 22.0 (IBM Corp.; Armonk, NY, USA) for descriptive statistical analyses. The average (range) was used for normally distributed parametric data, median (range) for those non-normally distributed parametric data, and percentage values for those with nonparametric data.

\section{HALO Vest Application}

The patient was placed in the supine position on the operating table. After cleaning the scalp with povidone-iodine, local anesthesia was applied to the places where the screw of the spiked head of the HALO Vest would come. The anterior screws were placed anterolaterally $1 \mathrm{~cm}$ above the orbital rim and 2/3 above the lateral of the orbit, and the posterior screws were placed in contact with the cranium on the opposite side of the anterior screws. The cervical alignment was controlled by scopy, the halo ring was combined with the lower jacket in the appropriate position, and the cranial screws were tightened to 6-8 lb. Once it was certain that the cervical alignment was improved after rechecking with scopy, the procedure was terminated.

\section{RESULTS}

A total of 30 (20 male and 10 female) patients who developed upper cervical vertebra fracture after spinal trauma and who had a HALO Vest immobilization device between 2013 and 2017 in our clinic were evaluated. Of the 30 patients, 2 had isolated $\mathrm{C} 1$ fractures, 6 had $\mathrm{C} 1+\mathrm{C} 2$ odontoid type 2 fractures, 16 had isolated odontoid fractures, 2 had C2 massa lateralis fractures, and 4 had hangman fractures. The ages of the patients evaluated in the study were between 29 and 89 (average 60) years. When the etiology of the patients were examined, it was found that 16 of them developed in-vehicle traffic accidents, 8 from falling from height, 4 from falling of a hard object to the head (work accident), and 2 developed fractures as a result of falling from their own height. Neurological examination revealed loss of strength in 8 patients. This force loss was as mild paresis in the right upper extremity in 5 patients and mild paresis in the left upper extremity in 3 patients. After HALO Vest application, partial improvement was observed in these patients. These eight patients with monoparesis were referred to the Physical Therapy and Rehabilitation Department after discharge. Systemic and local antibiotic treatment was started in $6(20 \%)$ of the 30 patients due to the development of infection at the screw site. The infection was resolved with treatment in 5 patients, whereas the infection was not improved in 1 patient; thus, the screw locations were changed, and the infection site was debrided.

It was accepted that 22 of the 30 patients who had undergone HALO Vest had sufficient fusion clinically and radiologically (Figure 1). The criteria for accepting the occurrence of radiological fusion are the absence of a fracture line, no movement on flexion-extension radiographs, and the occurrence of trabeculation of the fracture line. The fusion occurred on week 12 in 10 patients, week 14 in 6 patients, week 16 in 2 patients, week 18 in 2 patients, and week 20 in 2 patients. The average fusion time of these patients was 14.4 weeks. Surgery was recommended in 8 patients who did not develop fusion (Figure 2). Patients who did not accept surgery were followed with a cervical Philadelphia collar. Of the 8 patients without fusion, 6 (75\%) were odontoid type 2 fractures. Although no radiological fusion was observed in these 8 patients during the followup period, no regression was observed in their clinical picture. Neck pain completely disappeared in 16 patients who developed fusion, and there was a significant decrease in pain in 4 of them.

\section{DISCUSSION}

Today, upper cervical spine injuries caused by spinal traumas are still a major problem with respect to mortality and morbidity. Cervical fractures account for $>60 \%$ of spinal traumas (1). Approximately $2 \%-15 \%$ of acute cervical fractures are seen at the $\mathrm{C} 1$ level, and $17 \%-25 \%$ are seen at the C2 level (2). C1-C2 combined fractures constitute $3 \%$ of all cervical fractures (3). The fact is that the majority of the patients exposed to this trauma are in the very advanced age group, that they are dependent on bed during the treatment process and the length 


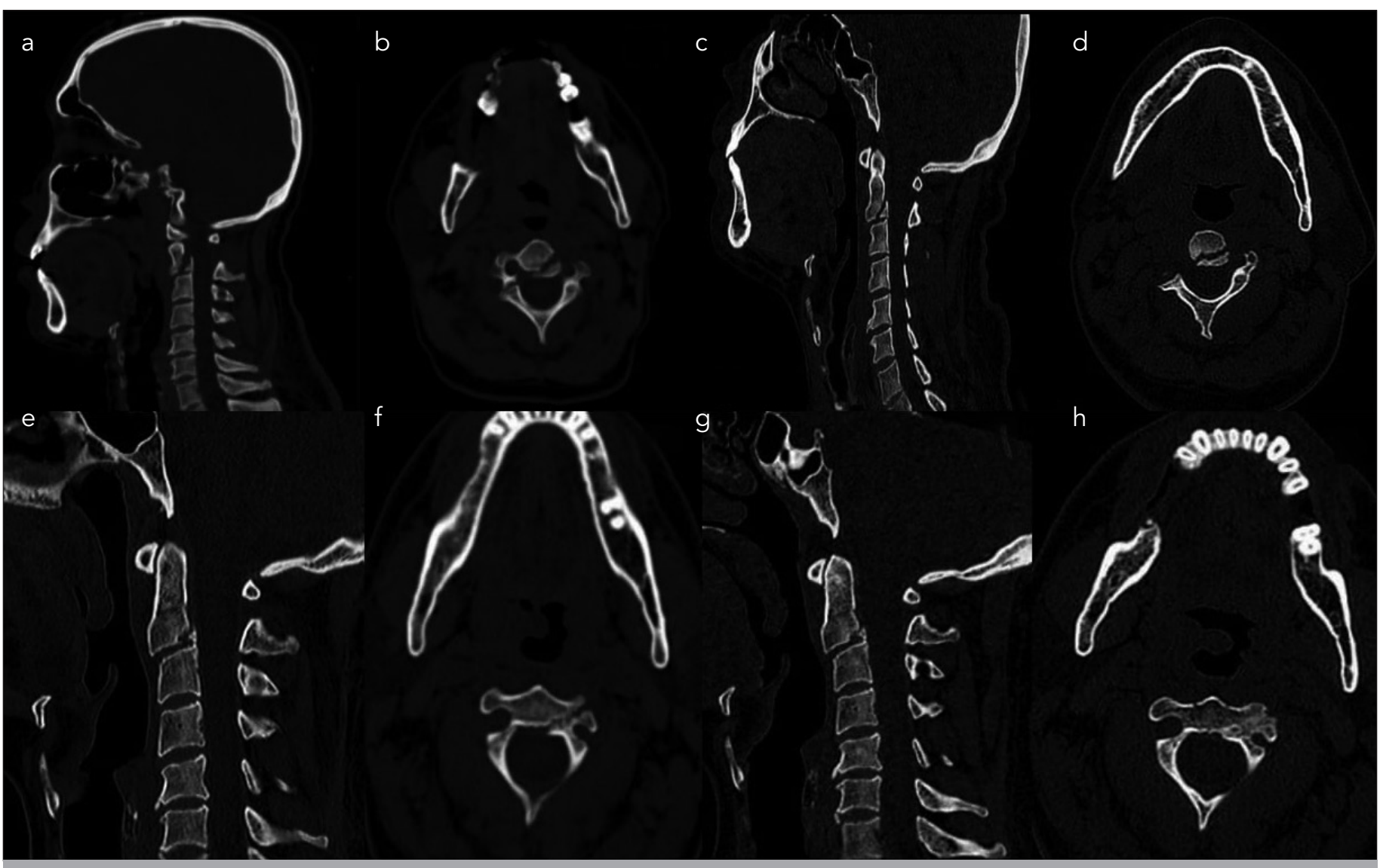

Figure 1. a-h. A 35-year-old male patient with no neurological deficit. Cervical computed tomography (CT) C2 fracture preop (a, b), month 1 control CT after HALO (c, d), month 3 control CT after HALO (e, f), and month 4 control CT after HALO ( $g, h)$
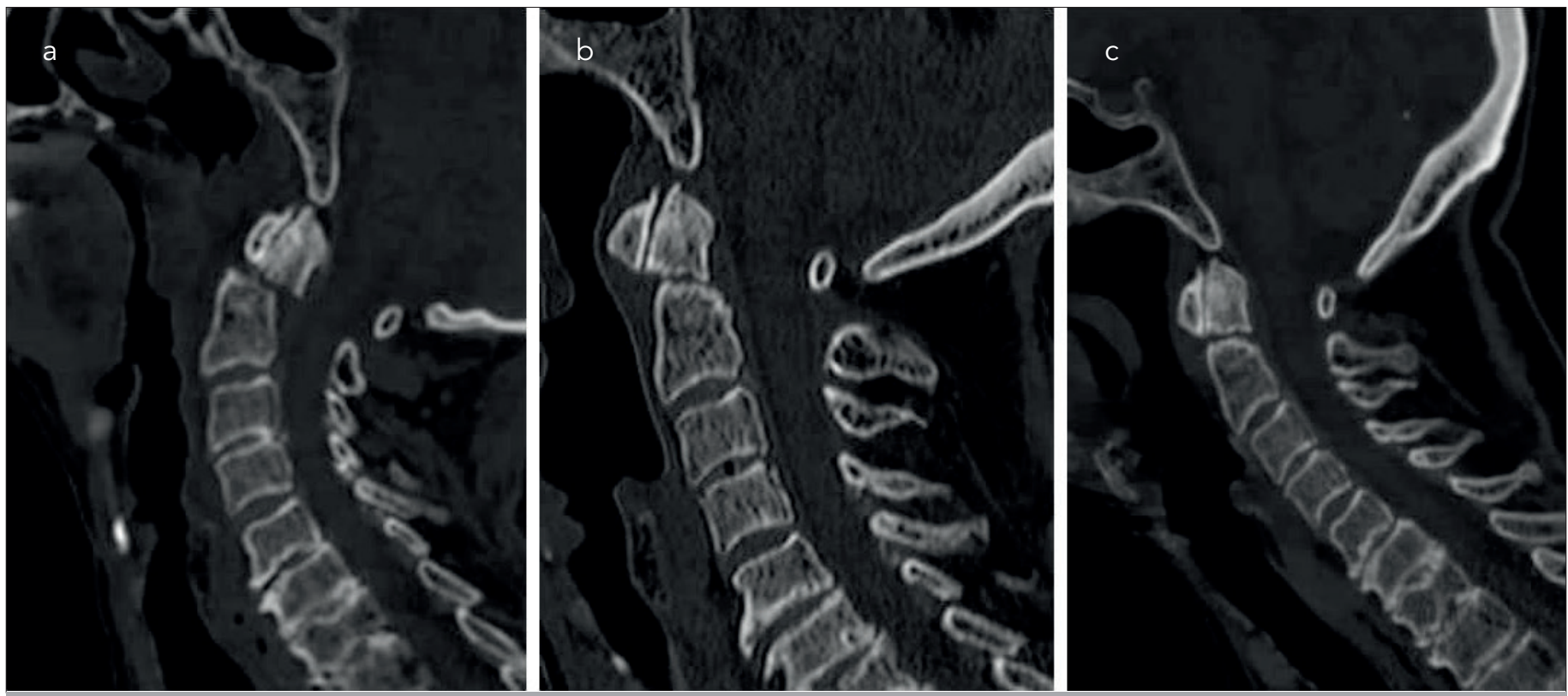

Figure 2. a-c. A 65-year-old female patient with no neurological deficit. Cervical computed tomography (CT) C2 fracture preop (a), month 1 control CT after HALO (b), and month 3 control CT after HALO (c)

of hospital stay is long, and that the complications that may occur consequently (decubitus wounds, joint contractures, and muscle atrophies) are serious problems. In recent years, these problems have been eliminated to a great extent with the application of a HALO Vest, which is a non-invasive treatment method with rising popularity. 
While the 12-week external immobilization is sufficient for isolated Atlas fractures, C1-C2 fusion is required for massa lateralis fractures with a separation $>7 \mathrm{~mm}$.

According to the Anderson D'Alonzo classification applied in odontoid fractures, the treatment options for type 1 and type 3 fractures are external immobilization, whereas surgery outweigh in type 2 fractures. External immobilization was recommended for patients with odontoid type 1 and type 3 fractures, and surgery was recommended for type 2 fractures. HALO Vest was implanted in patients who did not accept surgery.

The HALO Vest device is a reliable and successful method for patients with upper cervical vertebra fractures. It is a helpful treatment method that can be applied alone, as well as before or after surgery. With the HALO Vest device, rotation and lateral bending are well-controlled, and flexion and extension in the upper cervical spinal region are prevented up to $75 \%$ (5). Nevertheless, it should not be forgotten that cervical spinal movements may occur in a ratio of $25 \%-30 \%$ despite this device.

The fusion rate after HALO Vest application has been reported between $67 \%$ and $94 \%$ in the literature (6). In our patients, the fusion rate was found to be $73 \%$ in the postoperative follow-up and was consistent with the literature. Although the fracture healing time is reported as 3 months with the HALO Vest application, it can be extended to 4 months in elderly patients.

The failure rate in HALO Vest application varies between 18\% and $85 \%$ in the literature $(5,7)$. The main problem that may lead to failure in HALO Vest application during long-term follow-up is the problems that may occur at the screw site. Therefore, patients should be checked at regular intervals; the occurrence of infection or the loosening of the screws and the necessary intervention to be done immediately will increase the chance of successful treatment. HALO Vest application may result in failure in the presence of free disc or bone fragments and bilateral or unilateral facet locking in the radiological imaging. HALO Vest immobilization device should not be used in patients with severe cachectic and morbidly obese patients, patients with severe deformities, such as scoliosis and ankylosing spondylitis, and tetraplegic patients (5).

Various complications have been reported in the literature after HALO Vest application. These complications are screw loosening and displacement, infection and penetration at the screw site, compression wound due to HALO Vest's jacket, supraorbital and supratrochlear nerve injury, skull fracture, difficulty swallowing, myosis, cerebrospinal fluid fistula, cerebral hematoma, and cerebral abscess $(8,9)$. The most common complications are screw loosening and screw site infection. In our study, nail site infection was seen in 6 (20\%) patients, and 5 patients recovered without any problem with topical and systemic antibiotic treatment. The screw sites had to be relocated in one patient.
HALO Vest application is not an easy method to carry, especially in elderly patients due to incompatibility with the device. However, considering the systemic side effects of surgery in this age group, it is a good alternative treatment option. The success of $\mathrm{HALO}$ Vest treatment is directly proportional to the use of the device in appropriate indications and required patients. While the fusion rate is high, especially in isolated C1 fracture and odontoid type 1 fractures, the fusion rate decreases in odontoid type 2 fractures. Accordingly, in our study, 6 of the 8 patients without fusion were odontoid type 2 fractures.

\section{CONCLUSION}

While HALO Vest is a conservative treatment method that can be safely used alone when used with appropriate indication and when urgent reduction and immobilization is required in upper cervical vertebra fractures, it can also be applied in addition to surgery. Surgical options should be kept in mind, especially in odontoid type 2 fractures.

Ethics Committee Approval: Ethics committee approval was received for this study from the Ethics Committee of Clinical Research of Afyon Kocatepe University (03.02.2017-2017/2-40).

Informed Consent: Verbal informed consent was obtained from the patients who participated in this study.

Peer-review: Externally peer-reviewed.

Author Contributions: Concept - S.Y.; Design - S.Y..; Supervision - S.Y..; Resources M.G.B.; Data Collection and/or Processing - M.G.B.; Analysis and/or Interpretation - S.Y..; Literature Search - S.Y.; Writing Manuscript S.Y.; Critical Review - M.G.B.

Conflict of Interest: The authors have no conflict of interest to declare.

Financial Disclosure: The authors declared that this study has received no financial support.

\section{REFERENCES}

1. Shin JJ, Kim SJ, Kim TH, Shin HS, Hwang YS, Park SK. Optimal use of the halo- vest orthosis for upper cervical spine injuries. Yonsei Med J 2010; 51: 648-52. [CrossRef]

2. Longo UG, Denaro L, Campi S, Maffulli N, Denaro V. Upper cervical spine injuries: indications and limits of the conserva- tive management in Halo vest. A systematic review of efficacy and safety. Injury 2010; 41: 1127-35. [CrossRef]

3. Dickman CA, Hadley MN, Browner C, Sonntag VK. Neurosurgical management of acute atlas-axis com- bination fractures. A review of 25 cases. J Neurosurg 1989; 70: 45-9. [CrossRef]

4. Perry J, Nickel VL. Total cervical fusion for neck paralysis. J Bone Joint Surg 1959; 41: 37-60. [CrossRef]

5. Lauweryns P. Role of conservative treatment of cervical spine injuries. Eur Spine J 2010; 19(Suppl 1): 523-6. [CrossRef]

6. Vieweg $U$, Schultheiss R. A review of halo vest treat- ment of upper cervical spine injuries. Arch Orthop Trauma Surg 2001; 121: 50-5. [CrossRef]

7. Majercik S, Tashjian RZ, Biffl WL, Harrington D, Cioffi W. Halo Vest Immobilization in the Elderly: A Death Sentence? J Trauma 2005; 59: 350-6. [CrossRef] 
8. Garfin SR, Botte MJ, Waters RL, Nickel VL. Complications in the use of the halo fixation device. J Bone Joint Surg Am 1986; 68: 320-5. [CrossRef]
9. Bransford RJ, Stevens DW, Uyeji S, Bellabarba C, Chapman JR. Halo Vest treatment of cervical spine injuries. Spine 2009; 34: 1561-6. [CrossRef] 